Supporting Information

\title{
Electrolyte Additive-Driven Interfacial Engineering for High-Capacity Electrodes in Lithium-Ion Batteries: Promise and Challenges
}

Koeun Kim, Hyunsoo Ma, Sewon Park, and Nam-Soon Choi*

School of Energy and Chemical Engineering, Ulsan National Institute of Science and Technology (UNIST), 50, UNIST-gil, Ulsan 44919, Republic of Korea

Correspondence and requests for materials should be addressed to

N.-S.C. (E-mail: nschoi@unist.ac.kr). 
Table S1. Electrochemical performances of Ni-based cathodes at $25{ }^{\circ} \mathrm{C}$ with different electrolyte additives

\begin{tabular}{|c|c|c|c|c|c|}
\hline $\begin{array}{c}\text { Ni-rich cathode } \\
\text { type }^{\text {a) }}\end{array}$ & Additive $^{\text {b) }}$ & $\begin{array}{c}\text { Action } \\
\text { mechanism }\end{array}$ & Cell type & $\begin{array}{c}\text { Cycle retention } \\
(\%)\end{array}$ & Ref. \\
\hline NCM111 & TMB & Film formation & $\begin{array}{l}\mathrm{Li} / \mathrm{NCM} 111 \\
\quad(3.0-4.5)\end{array}$ & $\begin{array}{c}99 \\
(300 \text { cycles / 1 C) }\end{array}$ & 1 \\
\hline NCM111 & TEB & Film formation & $\begin{array}{c}\mathrm{Li} / \mathrm{NCM} 111 \\
(3.0-4.5 \mathrm{~V})\end{array}$ & $\begin{array}{c}100 \\
(150 \text { cycles / 1 C) }\end{array}$ & 2 \\
\hline NCM111 & TMSPi & $\begin{array}{l}\text { HF scavenging } \\
\text { /film formation }\end{array}$ & $\begin{array}{c}\mathrm{Li} / \mathrm{NCM} 111 \\
(3.0-4.5 \mathrm{~V})\end{array}$ & $\begin{array}{c}91 \\
(100 \text { cycles / } 0.5 \text { C) }\end{array}$ & 3 \\
\hline NCM523 & BDTD & Film formation & $\begin{array}{c}\mathrm{Li} / \mathrm{NCM} 523 \\
(3.0-4.6 \mathrm{~V})\end{array}$ & $\begin{array}{c}92 \\
(100 \text { cycles / } 0.5 \text { C) }\end{array}$ & 12 \\
\hline NCM523 & TMSPi & $\begin{array}{l}\text { HF scavenging } \\
\text { /film formation }\end{array}$ & $\begin{array}{c}\text { Full cell } \\
\text { (NCM523/graphite) } \\
(2.8-4.6 \mathrm{~V})\end{array}$ & $\begin{array}{c}62 \\
(160 \text { cycles / } 0.5 \text { C) }\end{array}$ & 13 \\
\hline NCM523 & PTSI & $\begin{array}{l}\text { HF scavenging } \\
\text { /film formation }\end{array}$ & $\begin{array}{c}\text { Li/NCM523 } \\
(3.0-4.6 \mathrm{~V})\end{array}$ & $\begin{array}{c}86 \\
(100 \text { cycles / 1 C) }\end{array}$ & 14 \\
\hline NCM622 & TIB & Film-formation & $\begin{array}{c}\mathrm{Li} / \mathrm{NCM} 622 \\
(3.0-4.5 \mathrm{~V})\end{array}$ & $\begin{array}{c}83 \\
(300 \text { cycles / } 1 \text { C) }\end{array}$ & 24 \\
\hline NCM622 & TMSPi & $\begin{array}{l}\text { HF scavenging } \\
\text { /film formation }\end{array}$ & $\begin{array}{c}\text { Full cell } \\
(\mathrm{NCM} 622 / \mathrm{MCMB}) \\
(2.8-4.45 \mathrm{~V})\end{array}$ & $\begin{array}{c}79 \\
(300 \text { cycles / } 1 \mathrm{C})\end{array}$ & 25 \\
\hline NCM622 & DPDMS & $\begin{array}{l}\text { HF scavenging } \\
\text { /film formation }\end{array}$ & $\begin{array}{c}\mathrm{Li} / \mathrm{NCM} 622 \\
(2.8-4.3 \mathrm{~V})\end{array}$ & $\begin{array}{c}99 \\
(200 \text { cycles / } 2 \text { C) }\end{array}$ & 26 \\
\hline NCM811 & SA & Film-formation & $\begin{array}{c}\mathrm{Li} / \mathrm{NCM} 811 \\
(2.8-4.3 \mathrm{~V})\end{array}$ & $\begin{array}{c}94 \\
(400 \text { cycles / } 1 \text { C) }\end{array}$ & 29 \\
\hline NCM811 & DODSi & $\begin{array}{l}\text { HF scavenging } \\
\text { /film formation }\end{array}$ & $\begin{array}{c}\mathrm{Li} / \mathrm{NCM} 811 \\
(3.0-4.3 \mathrm{~V})\end{array}$ & $\begin{array}{c}71 \\
(100 \text { cycles / } 1 \mathrm{C})\end{array}$ & 30 \\
\hline NCM811 & DODSi & $\begin{array}{l}\text { HF scavenging } \\
\text { /film formation }\end{array}$ & $\begin{array}{c}\mathrm{Li} / \mathrm{NCM} 811 \\
(3.0-4.5 \mathrm{~V})\end{array}$ & $\begin{array}{c}61 \\
(100 \text { cycles / } 1 \mathrm{C})\end{array}$ & 31 \\
\hline NCA & ABAPE & Film formation & $\begin{array}{c}\text { Full cell } \\
\text { (NCA/graphite) } \\
(2.75-4.2 \mathrm{~V})\end{array}$ & $\begin{array}{c}88 \\
(500 \text { cycles / 1 C) }\end{array}$ & 34 \\
\hline $\mathrm{NCA}$ & TMSPi & $\begin{array}{l}\text { HF scavenging } \\
\text { /film formation }\end{array}$ & $\begin{array}{c}\text { Full cell } \\
\text { (NCA/graphite) } \\
(3.0-4.2 \mathrm{~V})\end{array}$ & $\begin{array}{c}87 \\
(1000 \text { cycles / 1 C) }\end{array}$ & 35 \\
\hline $\mathrm{NCA}$ & DEPP & $\begin{array}{l}\text { HF scavenging } \\
\text { /film formation }\end{array}$ & $\begin{array}{c}\mathrm{Li} / \mathrm{NCA} \\
(3.0-4.35 \mathrm{~V})\end{array}$ & $\begin{array}{c}91 \\
(150 \text { cycles / 1 C) }\end{array}$ & 36 \\
\hline
\end{tabular}

${ }^{a} \mathrm{NCM}_{111}: \mathrm{LiNi}_{1 / 3} \mathrm{Co}_{1 / 3} \mathrm{Mn}_{1 / 3} \mathrm{O}_{2} ; \mathrm{NCM} 523: \mathrm{LiNi}_{0.5} \mathrm{Co}_{0.2} \mathrm{Mn}_{0.3} \mathrm{O}_{2} ; \mathrm{NCM} 622: \mathrm{LiNi}_{0.6} \mathrm{Co}_{0.2} \mathrm{Mn}_{0.2} \mathrm{O}_{2}$;

NCM811: $\mathrm{LiNi}_{0.8} \mathrm{Co}_{0.1} \mathrm{Mn}_{0.1} \mathrm{O}_{2} ; \mathrm{NCA}: \mathrm{LiNi}_{0.8} \mathrm{Co}_{0.15} \mathrm{Al}_{0.05} \mathrm{O}_{2}$.

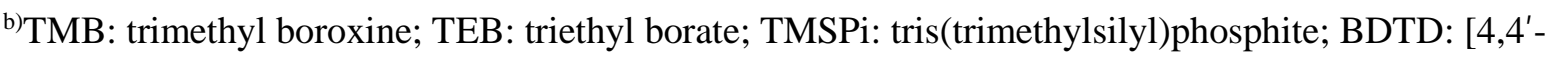
bi(1,3,2-dioxathiolane)]2,2'-dioxide; PTSI: $p$-toluenesulfonyl isocyanate; TIB: triisopropyl borate; DPDMS: diphenyldimethoxysilane; SA: succinic anhydride; DODSi: dimethoxydimethylsilane; ABAPE: allylboronic acid pinacol ester; DEPP: diethyl phenylphosphonite. 
Table S2. Representative additives for $\mathrm{LiNi}_{1 / 3} \mathrm{Co}_{1 / 3} \mathrm{Mn}_{1 / 3} \mathrm{O}_{2}(\mathrm{NCM} 111)$ cathodes

\begin{tabular}{|c|c|c|c|c|c|c|}
\hline Additive $^{a)}$ & $\begin{array}{c}\text { Action } \\
\text { mechanism }\end{array}$ & Cell type & $\begin{array}{c}\text { Cycle retention } \\
(\%)\end{array}$ & Structure & $\begin{array}{c}\text { CEI } \\
\text { structure }\end{array}$ & Ref. \\
\hline TMB & $\begin{array}{l}\text { Film } \\
\text { formation }\end{array}$ & $\begin{array}{l}\text { Li/NCM111 } \\
(3.0-4.5 \mathrm{~V})\end{array}$ & $\begin{array}{c}99 \\
(300 \text { cycles / 1.0 C) }\end{array}$ & & $\mathrm{B}-\mathrm{O}$ & 1 \\
\hline TEB & $\begin{array}{l}\text { Film } \\
\text { formation }\end{array}$ & $\begin{array}{l}\mathrm{Li} / \mathrm{NCM} 111 \\
(3.0-4.5 \mathrm{~V})\end{array}$ & $\begin{array}{c}100 \\
(150 \text { cycles / } \\
1 \mathrm{C})\end{array}$ & & $\mathrm{B}-\mathrm{O}$ & 2 \\
\hline TMSPi & $\begin{array}{c}\text { HF } \\
\text { scavenging } \\
\text { /film } \\
\text { formation }\end{array}$ & $\begin{array}{l}\mathrm{Li} / \mathrm{NCM} 111 \\
(3.0-4.5 \mathrm{~V})\end{array}$ & $\begin{array}{c}91 \\
(100 \text { cycles / } 0.5 \text { C) }\end{array}$ & & $\begin{array}{c}\text { Si-based, } \\
\text { P-based }\end{array}$ & 3 \\
\hline LiDMSI & $\begin{array}{l}\text { Film } \\
\text { formation }\end{array}$ & $\begin{array}{l}\mathrm{Li} / \mathrm{NCM} 111 \\
(3.0-4.6 \mathrm{~V})\end{array}$ & $\begin{array}{c}96 \\
\text { (47 cycles / 1 C) }\end{array}$ & & - & 4 \\
\hline LiBOB & $\begin{array}{l}\text { Film } \\
\text { formation }\end{array}$ & $\begin{array}{l}\mathrm{Li} / \mathrm{NCM} 111 \\
(3.0-4.6 \mathrm{~V})\end{array}$ & $\begin{array}{c}92 \\
(60 \text { cycles / 0.6 C) }\end{array}$ & & $\mathrm{B}-\mathrm{O}$ & 5 \\
\hline $\mathrm{TMB}^{*}$ & $\begin{array}{l}\text { Film } \\
\text { formation }\end{array}$ & $\begin{array}{l}\mathrm{Li} / \mathrm{NCM} 111 \\
(3.0-4.5 \mathrm{~V})\end{array}$ & $\begin{array}{c}89 \\
(200 \text { cycles / } 0.5 \text { C) }\end{array}$ & & $\mathrm{B}-\mathrm{O}$ & 6 \\
\hline LiDFOB & $\begin{array}{l}\text { Film } \\
\text { formation }\end{array}$ & $\begin{array}{l}\mathrm{Li} / \mathrm{NCM} 111 \\
(3.0-4.6 \mathrm{~V})\end{array}$ & $\begin{array}{c}88 \\
\text { (60 cycles / 0.6 C) }\end{array}$ & & $\mathrm{B}-\mathrm{O}$ & 5 \\
\hline EDPN & $\begin{array}{l}\text { Film } \\
\text { formation }\end{array}$ & $\begin{array}{c}\text { Full cell } \\
\text { (NCM111/graphite) } \\
(3.0-4.5 \mathrm{~V})\end{array}$ & $\begin{array}{c}84 \\
(100 \text { cycles / 1 C) }\end{array}$ & & N-based & 7 \\
\hline DMSM & $\begin{array}{l}\text { Film } \\
\text { formation }\end{array}$ & $\begin{array}{c}\text { Full cell } \\
\text { (NCM111/graphite) } \\
(3.0-4.6 \mathrm{~V})\end{array}$ & $\begin{array}{c}80 \\
(100 \text { cycles / 0.2 C) }\end{array}$ & & $\begin{array}{l}\mathrm{Li}_{2} \mathrm{SO}_{3} \\
\mathrm{ROSO}_{2} \mathrm{Li}\end{array}$ & 8 \\
\hline SDPN & $\begin{array}{l}\text { Film } \\
\text { formation }\end{array}$ & $\begin{array}{l}\mathrm{Li} / \mathrm{NCM} 111 \\
(3.0-4.6 \mathrm{~V})\end{array}$ & $\begin{array}{c}77 \\
(100 \text { cycles / 0.2 C) }\end{array}$ & & $\begin{array}{c}\mathrm{Li}_{2} \mathrm{SO}_{3}, \\
\mathrm{ROSO}_{2} \mathrm{Li}\end{array}$ & 9 \\
\hline TMSB & $\begin{array}{c}\text { Film } \\
\text { formation }\end{array}$ & $\begin{array}{l}\mathrm{Li} / \mathrm{NCM} 111 \\
(3.0-4.7 \mathrm{~V})\end{array}$ & $\begin{array}{c}72 \\
(150 \text { cycles / 1 C) }\end{array}$ & $\frac{1}{1-1}$ & $\begin{array}{l}\mathrm{C}-\mathrm{Si}-\mathrm{O}, \\
\text { B-based }\end{array}$ & 10 \\
\hline
\end{tabular}




\begin{tabular}{|c|c|c|c|c|c|c|}
\hline SL & $\begin{array}{c}\text { Film } \\
\text { formation }\end{array}$ & $\begin{array}{c}\text { Full cell } \\
(\text { NCM111/graphite }) \\
(3.0-4.6 \mathrm{~V})\end{array}$ & $\begin{array}{c}63 \\
(100 \text { cycles / 0.1 C) }\end{array}$ & \multirow{0}{*00}{} & S-O & 11 \\
\hline
\end{tabular}

a) TMB: trimethyl boroxine; TEB: triethyl borate; TMSPi: tris(trimethylsilyl)phosphite; LiDMSI:

lithium-cyclo-difluoromethane-1;1-bis(sulfonyl)imide; LiBOB: lithium bis(oxalato)borate; TMB*: trimethyl borate; LiDFOB: lithium difluoro(oxalato)borate; EDPN: 3,3'-

(ethylenedioxy)dipropionitrile; DMSM: di(methylsulfonyl)methane; SDPN: 3,3'-

sulfonyldipropionitrile; TMSB: tris(trimethylsilyl)borate; SL: sulfolane. 
Table S3. Representative additives for $\mathrm{LiNi}_{0.5} \mathrm{Co}_{0.2} \mathrm{Mn}_{0.3} \mathrm{O}_{2}(\mathrm{NCM} 523)$ cathodes

\begin{tabular}{|c|c|c|c|c|c|c|}
\hline Additive $^{a)}$ & $\begin{array}{c}\text { Action } \\
\text { mechanism }\end{array}$ & Cell type & $\begin{array}{c}\text { Cycle retention } \\
(\%)\end{array}$ & Structure & $\begin{array}{c}\text { CEI } \\
\text { structure }\end{array}$ & Ref. \\
\hline BDTD & $\begin{array}{c}\text { Film } \\
\text { formation }\end{array}$ & $\begin{array}{c}\mathrm{Li} / \mathrm{NCM} 523 \\
(3.0-4.6 \mathrm{~V})\end{array}$ & $\begin{array}{c}92 \\
(100 \text { cycles / } 0.5 \text { C) }\end{array}$ & & $\begin{array}{l}\mathrm{Li}_{2} \mathrm{SO}_{3} \\
\mathrm{RSO}_{3} \mathrm{Li} \\
\mathrm{ROSO}_{2} \mathrm{Li}\end{array}$ & 12 \\
\hline TMSPi & $\begin{array}{c}\mathrm{HF} \\
\text { scavenging } \\
\text { /film } \\
\text { formation }\end{array}$ & $\begin{array}{c}\text { Full cell } \\
\text { (NCM523/graphite) } \\
(2.8-4.6 \mathrm{~V})\end{array}$ & $\begin{array}{c}62 \\
(160 \text { cycles / } 0.5 \mathrm{C})\end{array}$ & & $\begin{array}{c}\mathrm{Li}_{x} \mathrm{PO}_{y} \mathrm{~F}_{z} \\
\mathrm{Li}_{x} \mathrm{PF}_{y}\end{array}$ & 13 \\
\hline PTSI & $\begin{array}{c}\mathrm{HF} \\
\text { scavenging } \\
\text { /film } \\
\text { formation }\end{array}$ & $\begin{array}{l}\mathrm{Li} / \mathrm{NCM} 523 \\
(3.0-4.6 \mathrm{~V})\end{array}$ & $\begin{array}{c}86 \\
(100 \text { cycles / 1 C) }\end{array}$ & & $\begin{array}{c}\mathrm{N}-\mathrm{C}, \mathrm{N}=\mathrm{C}, \\
\mathrm{N}-\mathrm{N}, \mathrm{N}-\mathrm{O}, \\
\mathrm{Li}_{2} \mathrm{~S} \\
\mathrm{Li}_{2} \mathrm{SO}_{3}, \\
\mathrm{Li}_{2} \mathrm{SO}_{4}\end{array}$ & 14 \\
\hline TMSP & $\begin{array}{c}\text { Film } \\
\text { formation }\end{array}$ & $\begin{array}{c}\text { Li/NCM523 } \\
(3.0-4.5 \mathrm{~V})\end{array}$ & $\begin{array}{c}91 \\
(100 \text { cycles / 1 C) }\end{array}$ & & $\begin{array}{l}\mathrm{Si}-\mathrm{O}, \\
\mathrm{P}-\mathrm{O}\end{array}$ & 15 \\
\hline $\begin{array}{l}\text { FEC, } \\
\text { DFEAc }\end{array}$ & $\begin{array}{c}\text { Film } \\
\text { formation }\end{array}$ & $\begin{array}{c}\mathrm{Li} / \mathrm{NCM} 523 \\
(3.0-4.6 \mathrm{~V})\end{array}$ & $\begin{array}{c}89 \\
(100 \text { cycles / 0.5 C) }\end{array}$ & & $\mathrm{C}-\mathrm{F}$ & 16 \\
\hline $\mathrm{ADN}$ & $\begin{array}{c}\text { Film } \\
\text { formation }\end{array}$ & $\begin{array}{c}\text { Full cell } \\
\text { (NCM523/graphite) } \\
(2.75-4.4 \mathrm{~V}) \\
\end{array}$ & $\begin{array}{c}85.2 \\
(120 \text { cycles / 1 C) }\end{array}$ & & N-based & 17 \\
\hline $\begin{array}{l}\text { FEC, } \\
\text { FEMC }\end{array}$ & $\begin{array}{c}\text { Film } \\
\text { formation }\end{array}$ & $\begin{array}{c}\text { Li/NCM523 } \\
(3.0-4.6 \mathrm{~V})\end{array}$ & $\begin{array}{c}84 \\
(50 \text { cycles / } 0.1 \mathrm{C})\end{array}$ & & $\begin{array}{l}\mathrm{CO}_{3} \\
\mathrm{CF}_{3}\end{array}$ & 18 \\
\hline TFEOP & $\begin{array}{c}\text { Film } \\
\text { formation }\end{array}$ & $\begin{array}{c}\text { Full cell } \\
\text { (NCM523/graphite) } \\
(3.0-4.6 \mathrm{~V})\end{array}$ & $\begin{array}{c}84 \\
(100 \text { cycles / C/3) }\end{array}$ & & $\begin{array}{c}\mathrm{CF}_{3}, \\
\text { phosphite, } \\
\mathrm{Li}_{x} \mathrm{PO}_{y} \mathrm{~F}_{z}, \\
\mathrm{LiPF}_{y}\end{array}$ & 19 \\
\hline IPDI & $\begin{array}{c}\text { Film } \\
\text { formation }\end{array}$ & $\begin{array}{c}\mathrm{Li} / \mathrm{NCM} 523 \\
(2.5-4.6 \mathrm{~V})\end{array}$ & $\begin{array}{c}83 \\
(200 \text { cycles / } \\
1 \text { C) }\end{array}$ & & N-based & 20 \\
\hline
\end{tabular}




\begin{tabular}{|c|c|c|c|c|c|c|}
\hline TEPi & $\begin{array}{c}\text { Film } \\
\text { formation }\end{array}$ & $\begin{array}{c}\text { Full cell } \\
\text { (NCM523/graphite) } \\
(3.0-4.4 \mathrm{~V})\end{array}$ & $\begin{array}{c}82 \\
(119 \text { cycles / } 0.1 \mathrm{C})\end{array}$ & & $\begin{array}{c}\mathrm{Li}_{x} \mathrm{PO}_{x} \mathrm{~F}_{z}, \\
\mathrm{Li}_{x} \mathrm{PF}_{y}\end{array}$ & 21 \\
\hline $\begin{array}{l}\text { FEC, } \\
\text { FEMC }\end{array}$ & $\begin{array}{c}\text { Film } \\
\text { formation }\end{array}$ & $\begin{array}{c}\text { Full cell } \\
\text { (NCM523/graphite) } \\
(3.0-4.5 \mathrm{~V})\end{array}$ & $\begin{array}{c}67 \\
(200 \text { cycles / 1 C) }\end{array}$ & & $\mathrm{CF}_{3}$ & 22 \\
\hline LiDFP & $\begin{array}{c}\text { Film } \\
\text { formation }\end{array}$ & $\begin{array}{c}\text { Full cell } \\
\text { (NCM523/graphite) } \\
(2.8-4.6 \mathrm{~V})\end{array}$ & $\begin{array}{c}62 \\
(160 \text { cycles / } 0.5 \mathrm{C})\end{array}$ & $\begin{array}{c}\mathrm{O} \\
\mathrm{F}-\mathrm{P}_{-}-\mathrm{Li}^{+} \\
\mathrm{F}\end{array}$ & $\mathrm{C}-\mathrm{F}, \mathrm{LiP}_{x} \mathrm{~F}_{y}$ & 23 \\
\hline
\end{tabular}

a) BDTD: [4,4'-bi(1,3,2-dioxathiolane)]2,2'-dioxide; TMSPi: tris(trimethylsilyl)phosphite; PTSI: ptoluenesulfonyl isocyanate; TMSP: tris(trimethylsilyl)phosphate; FEC: fluoroethylene carbonate; DFEAc: ethyl difluoroacetate; ADN: 1,4-dicyanobutane (adiponitrile); FEMC: methyl(2,2,2trifluoroethyl)carbonate; TFEOP: 2-(2,2,2-trifluoroethoxy)-1,3,2-dioxaphospholane-2-oxide; IPDI: qisophorone diisocyanate; TEPi: triethyl phosphite; LiDFP: lithium difluorophosphate. 
Table S4. Representative additives for $\mathrm{LiNi}_{0.6} \mathrm{Co}_{0.2} \mathrm{Mn}_{0.2} \mathrm{O}_{2}$ (NCM622) cathodes

\begin{tabular}{|c|c|c|c|c|c|c|}
\hline Additive $^{a}$ & $\begin{array}{c}\text { Action } \\
\text { mechanism }\end{array}$ & Cell type & $\begin{array}{c}\text { Cycle } \\
\text { retention (\%) }\end{array}$ & Structure & CEI moiety & Ref. \\
\hline TIB & $\begin{array}{l}\text { Film } \\
\text { formation }\end{array}$ & $\begin{array}{c}\mathrm{Li} / \mathrm{NCM} 622 \\
(3.0-4.5 \mathrm{~V})\end{array}$ & $\begin{array}{c}83 \\
(300 \text { cycles / } \\
1 \text { C) }\end{array}$ & & $\mathrm{B}-\mathrm{O}$ & 24 \\
\hline TMSPi & $\begin{array}{c}\mathrm{HF} \\
\text { scavenging } \\
\text { /film } \\
\text { formation }\end{array}$ & $\begin{array}{c}\text { Full cell } \\
\text { (NCM622/MC } \\
\mathrm{MB}) \\
(2.8-4.45 \mathrm{~V})\end{array}$ & $\begin{array}{c}79 \\
(300 \text { cycles / } \\
1 \text { C) }\end{array}$ & & $\begin{array}{l}\mathrm{Si}-\mathrm{F}, \\
\mathrm{Si}-\mathrm{O}\end{array}$ & 25 \\
\hline DPDMS & $\begin{array}{c}\mathrm{HF} \\
\text { scavenging } \\
\text { /film } \\
\text { formation }\end{array}$ & $\begin{array}{c}\mathrm{Li} / \mathrm{NCM} 622 \\
(2.8-4.3 \mathrm{~V})\end{array}$ & $\begin{array}{c}99 \\
(200 \text { cycles / } \\
2 \text { C) }\end{array}$ & & $\begin{array}{l}\mathrm{Si}-\mathrm{F}, \\
\mathrm{Si}-\mathrm{O}\end{array}$ & 26 \\
\hline IPDS & $\begin{array}{c}\mathrm{HF} \\
\text { scavenging } \\
\text { /film } \\
\text { formation }\end{array}$ & $\begin{array}{c}\mathrm{Li} / \mathrm{NCM} 622 \\
(2.5-4.5 \mathrm{~V})\end{array}$ & $\begin{array}{c}73 \\
(150 \text { cycles / } \\
0.3 \mathrm{C})\end{array}$ & & $\begin{array}{l}\mathrm{Si}-\mathrm{F}, \\
\mathrm{Si}-\mathrm{O}\end{array}$ & 27 \\
\hline LiDFP & $\begin{array}{l}\text { Film } \\
\text { formation }\end{array}$ & $\begin{array}{c}\text { Full cell } \\
\text { (NCM622/Gra } \\
\text { phite) } \\
(2.8-4.2 \mathrm{~V})\end{array}$ & $\begin{array}{c}89 \\
(500 \text { cycles / } \\
1.5 \mathrm{C})\end{array}$ & $\underset{\substack{\mathrm{O}-\mathrm{O} \\
\mathrm{P}}}{\mathrm{L}} \mathrm{O}^{\mathrm{Li}^{+}}$ & $\begin{array}{l}\mathrm{P}-\mathrm{O}, \\
\mathrm{O}-\mathrm{P}-\mathrm{F}\end{array}$ & 28 \\
\hline
\end{tabular}

a) TIB: triisopropyl borate; TMSPi: tris(trimethylsilyl)phosphite; DPDMS: diphenyldimethoxysilane; IPTS: 3-isocyanatopropyltriethoxysilane; LiDFP: lithium difluorophosphate. 
Table S5. Representative additives for $\mathrm{LiNi}_{0.8} \mathrm{Co}_{0.1} \mathrm{Mn}_{0.1} \mathrm{O}_{2}(\mathrm{NCM} 811)$ cathodes

\begin{tabular}{|c|c|c|c|c|c|c|}
\hline Additive $^{a)}$ & $\begin{array}{c}\text { Action } \\
\text { mechanism }\end{array}$ & Cell type & $\begin{array}{c}\text { Cycle } \\
\text { retention (\%) }\end{array}$ & Structure & CEI moiety & Ref. \\
\hline SA & $\begin{array}{c}\text { Film } \\
\text { formation }\end{array}$ & $\begin{array}{c}\mathrm{Li} / \mathrm{NCM} 811 \\
(2.8-4.3 \mathrm{~V})\end{array}$ & $\begin{array}{c}94 \\
(400 \text { cycles / } \\
1 \text { C) }\end{array}$ & & $\operatorname{Poly}\left(\mathrm{CO}_{3}\right)$ & 29 \\
\hline DODSi & $\begin{array}{c}\mathrm{HF} \\
\text { scavenging } \\
\text { /film } \\
\text { formation }\end{array}$ & $\begin{array}{c}\mathrm{Li} / \mathrm{NCM} 811 \\
(3.0-4.3 \mathrm{~V})\end{array}$ & $\begin{array}{c}71 \\
(100 \text { cycles / } \\
1 \mathrm{C})\end{array}$ & & $\mathrm{Si}-\mathrm{O}$ & 30 \\
\hline DODSi & $\begin{array}{c}\text { HF } \\
\text { scavenging } \\
\text { /film } \\
\text { formation }\end{array}$ & $\begin{array}{c}\mathrm{Li} / \mathrm{NCM} 811 \\
(3.0-4.5 \mathrm{~V})\end{array}$ & $\begin{array}{c}61 \\
(100 \text { cycles / } \\
1 \text { C) }\end{array}$ & & $\mathrm{Si}-\mathrm{O}$ & 31 \\
\hline ТРPO & $\begin{array}{l}\text { Film } \\
\text { formation }\end{array}$ & $\begin{array}{c}\text { Full cell } \\
\text { (NCM811/gra } \\
\text { phite) } \\
(2.8-4.3 \mathrm{~V})\end{array}$ & $\begin{array}{c}92 \\
(100 \text { cycles / } \\
0.5 \mathrm{C})\end{array}$ & & P-based & 32 \\
\hline PES & $\begin{array}{c}\text { Film } \\
\text { formation }\end{array}$ & $\begin{array}{c}\text { Full cell } \\
\text { (NCM811/gra } \\
\text { phite) } \\
(2.78-4.1 \mathrm{~V})\end{array}$ & $\begin{array}{c}91 \\
\text { (80 cycles / } \\
0.5 \mathrm{C})\end{array}$ & o" & - & 33 \\
\hline
\end{tabular}

a) SA: succinic anhydride; DODSi: dimethoxy dimethyl silane; TPPO: triphenylphosphine oxide; PES: prop-1-ene-1,3-sultone. 
Table S6. Representative additives for $\mathrm{LiNi}_{0.8} \mathrm{Co}_{0.15} \mathrm{Al}_{0.05} \mathrm{O}_{2}(\mathrm{NCA})$ cathodes

\begin{tabular}{|c|c|c|c|c|c|c|}
\hline Additive $^{a)}$ & $\begin{array}{c}\text { Action } \\
\text { mechanism }\end{array}$ & Cell type & $\begin{array}{c}\text { Cycle } \\
\text { retention }(\%)\end{array}$ & Structure & $\begin{array}{c}\text { CEI } \\
\text { moiety }\end{array}$ & Ref. \\
\hline ABAPE & $\begin{array}{l}\text { Film } \\
\text { formation }\end{array}$ & $\begin{array}{c}\text { Full cell } \\
\text { (NCA/graphite) } \\
(2.75-4.2 \mathrm{~V})\end{array}$ & $\begin{array}{c}88 \\
(500 \text { cycles / } \\
1 \mathrm{C})\end{array}$ & & $\mathrm{B}-\mathrm{O}$ & 34 \\
\hline TMSPi & $\begin{array}{c}\mathrm{HF} \\
\text { scavenging } \\
\text { /film } \\
\text { formation }\end{array}$ & $\begin{array}{c}\text { Full cell } \\
\text { (NCA/graphite) } \\
(3.0-4.2 \mathrm{~V})\end{array}$ & $\begin{array}{c}87 \\
(1000 \text { cycles / } \\
1 \text { C) }\end{array}$ & & $\mathrm{P}-\mathrm{O}-\mathrm{Si}$ & 35 \\
\hline DEPP & $\begin{array}{c}\text { HF } \\
\text { scavenging } \\
\text { /film } \\
\text { formation }\end{array}$ & $\begin{array}{c}\mathrm{Li} / \mathrm{NCA} \\
(3.0-4.35 \mathrm{~V})\end{array}$ & $\begin{array}{c}91 \\
(150 \text { cycles / } \\
1 \mathrm{C})\end{array}$ & & $\mathrm{P}-\mathrm{O}$ & 36 \\
\hline TPP & $\begin{array}{l}\text { Film } \\
\text { formation }\end{array}$ & $\begin{array}{c}\mathrm{Li} / \mathrm{NCA} \\
(3.0-4.2 \mathrm{~V})\end{array}$ & $\begin{array}{c}99 \\
(20 \text { cycles / } \\
0.05 \mathrm{C})\end{array}$ & & - & 37 \\
\hline NNB & $\begin{array}{l}\text { Film } \\
\text { formation }\end{array}$ & $\begin{array}{c}\text { Full cell } \\
\text { (NCA/graphite) } \\
(3.0-4.2 \mathrm{~V})\end{array}$ & $\begin{array}{c}86 \\
(300 \text { cycles / } \\
1 \text { C) }\end{array}$ & & $\begin{array}{l}\mathrm{C}-\mathrm{N}, \\
\mathrm{Si}-\mathrm{N} \\
\mathrm{Si}-\mathrm{C}\end{array}$ & 38 \\
\hline BTMSEFM & $\begin{array}{c}\mathrm{HF} \\
\text { scavenging }\end{array}$ & $\begin{array}{c}\text { Full cell } \\
\text { (NCA/graphite) } \\
(3.0-4.5 \mathrm{~V})\end{array}$ & $\begin{array}{c}44 \\
(100 \text { cycles / } \\
0.5 \mathrm{C})\end{array}$ & & $\mathrm{C}_{\mathrm{X}} \mathrm{F}$ & 39 \\
\hline
\end{tabular}

a) ABAPE: allylboronic acid pinacol ester; TMSPi: tris(trimethylsilyl)phosphite; DEPP: diethyl phenylphosphonite; TPP: triphenyl phosphate; NNB: $N$-allyl- $N, N$-bis(trimethylsilyl)amine; BTMSEFM: 2-ethyl-2-fluoromalonate. 
Table S7. Representative additives for Si anodes

\begin{tabular}{|c|c|c|c|c|c|c|}
\hline Additive $^{\text {a) }}$ & Anode & Cell type & $\begin{array}{c}\text { Cycle } \\
\text { retention }(\%)\end{array}$ & Structure & $\begin{array}{c}\text { SEI } \\
\text { structure }\end{array}$ & Ref. \\
\hline ТРFPB & $\begin{array}{l}\text { Silicon thin } \\
\quad \text { film }\end{array}$ & $\begin{array}{c}\mathrm{Li} / \mathrm{Si} \\
(0.005-1.5 \mathrm{~V})\end{array}$ & $\begin{array}{c}87.2 \\
(100 \text { cycles / } \\
0.5 \mathrm{C})\end{array}$ & & $\begin{array}{c}\mathrm{LiF}, \mathrm{C}-\mathrm{F}, \\
\mathrm{Li}_{2} \mathrm{CO}_{3}, \\
\text { hydrocarbon }\end{array}$ & 40 \\
\hline LiDFOB & $\begin{array}{l}\text { Silicon/graphit } \\
\text { e (Si-C) }\end{array}$ & $\begin{array}{c}\text { Full cell } \\
\text { (LCO-NMC/ } \\
\text { Si-C) } \\
(3-4.5 \mathrm{~V})\end{array}$ & $\begin{array}{c}90 \\
(50 \text { cycles / } \\
0.5 \mathrm{C})\end{array}$ & & $\mathrm{LiF}$ & 41 \\
\hline TFPC & Si nanoparticle & $\begin{array}{c}\mathrm{Li} / \mathrm{Si} \\
(0.01-1 \mathrm{~V})\end{array}$ & $\begin{array}{c}52 \\
(200 \text { cycles / } \\
0.1 \mathrm{C})\end{array}$ & & $\begin{array}{c}\text { LiF, } \\
\text { Polyolefin }\end{array}$ & 42 \\
\hline FEC & $\begin{array}{l}\text { Silicon thin } \\
\quad \text { film }\end{array}$ & $\begin{array}{c}\mathrm{Li} / \mathrm{Si} \\
(0.005-2 \mathrm{~V})\end{array}$ & $\begin{array}{c}88.5 \\
(80 \text { cycles / } \\
0.2 \mathrm{C})\end{array}$ & & $\mathrm{LiF},-\mathrm{Si}-\mathrm{F}$ & 43 \\
\hline $\mathrm{VC}$ & N-type Si film & $\begin{array}{c}\mathrm{Li} / \mathrm{Si} \\
(0-1.5 \mathrm{~V})\end{array}$ & $\begin{array}{c}50 \\
\text { (500 cycles / } \\
\text { unknown) }\end{array}$ & & $\begin{array}{l}\text { Poly }(\mathrm{VC}), \\
\text { polycarbonate }\end{array}$ & 44 \\
\hline LiBOB & $\begin{array}{l}\text { Silicon thin } \\
\quad \text { film }\end{array}$ & $\begin{array}{c}\mathrm{Li} / \mathrm{Si} \\
(0.005-1.3 \mathrm{~V})\end{array}$ & $\begin{array}{c}65 \\
(55 \text { cycles / } \\
0.2 \mathrm{C})\end{array}$ & & $\begin{array}{l}\text { Oxalates, } \\
\mathrm{Li}_{\mathrm{x}} \mathrm{PF}_{\mathrm{y}} \mathrm{O}_{z}\end{array}$ & 45 \\
\hline SA & $\begin{array}{l}\text { Silicon thin } \\
\quad \text { film }\end{array}$ & $\begin{array}{c}\mathrm{Li} / \mathrm{Si} \\
(0.005-1.5 \mathrm{~V})\end{array}$ & $\begin{array}{c}80 \\
(100 \text { cycles / } \\
0.5 \mathrm{C})\end{array}$ & & $\begin{array}{c}\mathrm{Li}_{2} \mathrm{CO}_{3}, \\
\text { Hydrocarbons }\end{array}$ & 46 \\
\hline PFPI & $\begin{array}{l}\text { Silicon thin } \\
\quad \text { film }\end{array}$ & $\begin{array}{c}\text { Full cell } \\
\text { (NCM111/ } \\
\text { Si) } \\
(3-4.3 \mathrm{~V})\end{array}$ & $\begin{array}{c}44.6 \\
(103 \text { cycles / } \\
1 \text { C) }\end{array}$ & & $\begin{array}{c}\text { Fluorinated } \\
\text { organic } \\
\text { species, C-N, } \\
\text { C-O, C-F }\end{array}$ & 47 \\
\hline MEC & $\begin{array}{l}\text { Silicon thin } \\
\quad \text { film }\end{array}$ & $\begin{array}{c}\mathrm{Li} / \mathrm{Si} \\
(0.005-1.5 \mathrm{~V})\end{array}$ & $\begin{array}{c}73 \\
(100 \text { cycles / } \\
\text { C/3) }\end{array}$ & & $\begin{array}{c}\text { Poly(MEC), } \\
\mathrm{Li}_{2} \mathrm{CO}_{3}, \mathrm{Li} \\
\text { carboxylate }\end{array}$ & 48 \\
\hline
\end{tabular}




\begin{tabular}{|c|c|c|c|c|c|c|}
\hline VTMS & $\begin{array}{c}\mathrm{Si} / \mathrm{C} \\
\text { composite }\end{array}$ & $\begin{array}{c}\mathrm{Li} /(\mathrm{Si} / \mathrm{C}) \\
(0.005-1.5 \mathrm{~V})\end{array}$ & $\begin{array}{c}96.1 \\
(50 \text { cycles / } \\
0.1 \mathrm{C})\end{array}$ & & $\begin{array}{c}\text { Organosilicon } \\
\text { compounds, } \\
\mathrm{Li}_{2} \mathrm{CO}_{3}, \mathrm{LiF}\end{array}$ & 49 \\
\hline TEOSCN & $\begin{array}{c}\text { Si alloy + } \\
\text { Artificial } \\
\text { graphite }\end{array}$ & $\begin{array}{c}\text { Full cell } \\
\text { (NCM622/ } \\
\text { Si alloy }+ \\
\text { Artificial } \\
\text { graphite) } \\
(2.5-4.2 \mathrm{~V})\end{array}$ & $\begin{array}{c}58.3 \\
(417 \text { cycles / } \\
1 \mathrm{C} / 0.5 \mathrm{C})\end{array}$ & & $\begin{array}{l}\text { Protective } \\
\text { siloxane } \\
\text { network }\end{array}$ & 50 \\
\hline $\begin{array}{l}\text { TMMS, } \\
\text { DMDMS, } \\
\text { MTMS }\end{array}$ & $\begin{array}{c}\text { Silicon } \\
\text { deposited } \\
\text { EQCM }\end{array}$ & $\begin{array}{c}\mathrm{Li} / \mathrm{Si} \\
(0.01-1.5 \mathrm{~V})\end{array}$ & $\begin{array}{c}>94 \\
(10 \text { cycles / } \\
1 \mathrm{C})\end{array}$ & & Alkoxy silane & 51 \\
\hline DFDEC & $\begin{array}{c}\mathrm{Si}-\mathrm{G} \\
\text { composite }\end{array}$ & $\begin{array}{c}\mathrm{Li} / \mathrm{Si}-\mathrm{G} \\
(0.01-1.5 \mathrm{~V})\end{array}$ & $\begin{array}{c}78 \\
(50 \text { cycles / } \\
0.2 \mathrm{C})\end{array}$ & & $\begin{array}{c}\mathrm{Li}_{2} \mathrm{CO}_{3}, \mathrm{LiF}, \\
\mathrm{OPF}_{3-y}(\mathrm{OR})_{y}, \\
\mathrm{Li}_{x} \mathrm{PF}_{y} \mathrm{O}_{z}\end{array}$ & 52 \\
\hline PCS & $\mathrm{SiO}_{x}-\mathrm{C}$ & $\begin{array}{c}\text { Full cell } \\
(\mathrm{LNMO} / \\
\left.\mathrm{SiO}_{\mathrm{x}}-\mathrm{C}\right) \\
(3.5-4.9 \mathrm{~V})\end{array}$ & $\begin{array}{c}79.8 \\
(100 \text { cycles / } \\
0.2 \mathrm{C})\end{array}$ & & $\begin{array}{l}\mathrm{LiF} \text {, sulfates, } \\
\text { organic } \\
\text { sulfites }\end{array}$ & 53 \\
\hline LiFMDFB & Si-graphite & $\begin{array}{l}\text { Full cell } \\
\text { (Li-rich/Si- } \\
\text { graphite) } \\
(2-4.55 \mathrm{~V})\end{array}$ & $\begin{array}{c}85 \\
(100 \text { cycles / } \\
0.5 \mathrm{C})\end{array}$ & & $\begin{array}{c}\mathrm{LiF}, \mathrm{O}=\mathrm{CO}_{2} \\
\mathrm{O}=\mathrm{C}-\mathrm{O}\end{array}$ & 54 \\
\hline
\end{tabular}

a) TPFPB: tris(pentafluorophenyl)borane; LiDFOB: lithium difluoro(oxalato)borate; TFPC:

trifluoropropylene carbonate; FEC: fluoroethylene carbonate; VC: vinylene carbonate; LiBOB:

lithium bis(oxalato)borate; SA: succinic anhydride; PFPI: pentafluorophenyl isocyanate; MEC:

methylene ethylene carbonate; VTMS: vinyl tris(2-methoxyethoxy) silane; TMMS:

trimethoxymethylsilane; DMDMS: dimethoxydimethylsilane; MTMS: methoxytrimethylsilane;

DFDEC: di(2,2,2-trifluoroethyl)carbonate; PCS: 1,3-propanediolcyclic sulfate; LiFMDFB: lithium fluoromalonato(difluoro)borate. 
Table S8. Representative additives for suppressing gas generation in batteries

\begin{tabular}{|c|c|c|c|c|c|c|}
\hline Additive $^{a)}$ & $\begin{array}{c}\text { Action } \\
\text { mechanism }\end{array}$ & Cell type & $\begin{array}{c}\text { Cycle } \\
\text { retention }(\%)\end{array}$ & Structure & $\begin{array}{c}\text { CEI/SEI } \\
\text { structure }\end{array}$ & Ref. \\
\hline LiFMDFB & $\begin{array}{c}\mathrm{O}_{2} \text { scavenging } \\
\quad / \text { film } \\
\text { formation }\end{array}$ & $\begin{array}{c}\text { Full cell } \\
\text { (Li-rich/Si- } \\
\text { graphite) } \\
(2.0-4.55 \mathrm{~V})\end{array}$ & $\begin{array}{c}85 \\
(100 \text { cycles / } \\
0.5 \mathrm{C})\end{array}$ & & $\begin{array}{c}\mathrm{Li}_{2} \mathrm{CO}_{3} \\
\mathrm{CH}_{2}- \\
\mathrm{OCO}_{2} \mathrm{Li} \\
\mathrm{C}=\mathrm{O} \\
\mathrm{C}-\mathrm{O}-\mathrm{C} \\
(\mathrm{CEI})\end{array}$ & 54 \\
\hline TPP & $\mathrm{O}_{2}$ scavenging & $\begin{array}{c}\text { Full cell } \\
\text { (LCO-Li-rich/ } \\
\text { graphite) } \\
(2.75-4.53 \mathrm{~V})\end{array}$ & $\begin{array}{c}42 \\
(300 \text { cycles / } \\
0.5 \mathrm{C})\end{array}$ & & - & 55 \\
\hline EDP & $\mathrm{O}_{2}$ scavenging & $\begin{array}{c}\text { Full cell } \\
\text { (LCO-Li-rich/ } \\
\text { graphite) } \\
(2.75-4.53 \mathrm{~V})\end{array}$ & $\begin{array}{c}45 \\
(300 \text { cycles / } \\
0.5 \mathrm{C})\end{array}$ & & - & 55 \\
\hline TEP & $\mathrm{O}_{2}$ scavenging & $\begin{array}{c}\text { Full cell } \\
\text { (LCO-Li-rich/ } \\
\text { graphite) } \\
(2.75-4.53 \mathrm{~V})\end{array}$ & $\begin{array}{c}56 \\
(300 \text { cycles / } \\
0.5 \mathrm{C})\end{array}$ & & - & 55 \\
\hline SN & $\begin{array}{c}\text { Film } \\
\text { formation }\end{array}$ & $\begin{array}{l}\text { Full cell } \\
\text { (LCO/ } \\
\text { graphite) } \\
(3.0-4.2 \mathrm{~V})\end{array}$ & $\begin{array}{c}90 \\
(280 \text { cycles / } \\
1 \text { C) }\end{array}$ & & $\begin{array}{c}\text { N-based } \\
\text { (CEI) }\end{array}$ & 56 \\
\hline DPDS & $\begin{array}{c}\text { Film } \\
\text { formation }\end{array}$ & $\begin{array}{l}\text { Full cell } \\
\text { (Li-rich/ } \\
\text { graphite) } \\
(3.0-4.4 \mathrm{~V})\end{array}$ & $\begin{array}{c}68.4 \\
(100 \text { cycles / } \\
1 \mathrm{C})\end{array}$ & & $\begin{array}{c}\text { S-based } \\
\text { (CEI/SEI) }\end{array}$ & 57 \\
\hline PS & $\begin{array}{c}\text { Film } \\
\text { formation }\end{array}$ & $\begin{array}{c}\text { Full cell } \\
\left(\text { LNMO }^{\mathrm{b})} /\right. \\
\text { graphite }) \\
(3.0-4.8 \mathrm{~V})\end{array}$ & $\begin{array}{c}60 \\
(200 \text { cycles / } \\
0.5 \mathrm{C})\end{array}$ & & $\begin{array}{c}\mathrm{Li}_{2} \mathrm{SO}_{3}, \\
\mathrm{LiO}_{3} \mathrm{~S}- \\
\left(\mathrm{CH}_{2}\right)_{6}- \\
\mathrm{SO}_{3} \mathrm{Li} \\
(\mathrm{SEI})\end{array}$ & 58 \\
\hline $\mathrm{VC}$ & $\begin{array}{c}\text { Film } \\
\text { formation }\end{array}$ & $\begin{array}{c}\text { Full cell } \\
\text { (NCM111/ } \\
\text { graphite) } \\
(3.0-4.2 \mathrm{~V})\end{array}$ & $\begin{array}{c}62.1 \\
(50 \text { cycles / } \\
0.2 \mathrm{C})\end{array}$ & & $\begin{array}{l}\text { poly }(\mathrm{VC}) \\
(\mathrm{SEI})\end{array}$ & 59 \\
\hline
\end{tabular}

a) LiFMDFB: lithium fluoromalonato(difluoro)borate; TPP: triphenyl phosphine; EDP: ethyl diphenylphosphinite; TEP: triethyl phosphite; SN: succinonitrile; DPDS: diphenyl disulfide; PS: 1,3propane sultone; $\mathrm{VC}$ : vinylene carbonate.

b) LNMO: $\mathrm{LiNi}_{0.5} \mathrm{Mn}_{1.5} \mathrm{O}_{4}$. 
Table S9. Additives adapted to cells with NCM cathodes and Si anodes

\begin{tabular}{|c|c|c|c|c|c|}
\hline Additive $^{a)}$ & Cell type & $\begin{array}{c}\text { Cycle retention } \\
(\%)\end{array}$ & $\begin{array}{c}\text { CEI } \\
\text { structure }\end{array}$ & $\begin{array}{c}\text { SEI } \\
\text { structure }\end{array}$ & Ref. \\
\hline LiDFOB & $\begin{array}{c}\text { Full cell } \\
(\mathrm{LCO}-\mathrm{NMC} / \mathrm{Si}-\mathrm{C}) \\
(3-4.5 \mathrm{~V})\end{array}$ & $\begin{array}{c}90 \\
\text { (50 cycles / 0.5 C) }\end{array}$ & $\mathrm{B}-\mathrm{O}$ & $\mathrm{LiF}$ & 41 \\
\hline PFPI & $\begin{array}{c}\text { Full cell } \\
(\mathrm{NCM} 111 / \mathrm{Si}) \\
(3-4.3 \mathrm{~V})\end{array}$ & $\begin{array}{c}44.6 \\
(103 \text { cycles / 1 C) }\end{array}$ & - & $\begin{array}{l}\text { Fluorinated } \\
\text { organic } \\
\text { species, C-N, } \\
\text { C-O, C-F }\end{array}$ & 47 \\
\hline TEOSCN & $\begin{array}{c}\text { Full cell } \\
\text { (NCM622/Si alloy }+ \\
\text { Artificial graphite) } \\
(2.5-4.2 \mathrm{~V})\end{array}$ & $\begin{array}{c}58.3 \\
(417 \text { cycles / } \\
1 \mathrm{C} / 0.5 \mathrm{C})\end{array}$ & - & $\begin{array}{l}\text { Protective } \\
\text { siloxane } \\
\text { network }\end{array}$ & 50 \\
\hline TMSPi & $\begin{array}{c}\text { Full cell } \\
\left(\mathrm{NCM}^{2} 2 /\right. \\
\left.\mathrm{SiO}_{x}+\text { graphite }\right) \\
(2.8-4.25 \mathrm{~V})\end{array}$ & $\begin{array}{c}99.0 \\
(200 \text { cycles / 1 C) }\end{array}$ & $\begin{array}{l}\mathrm{Li}_{2} \mathrm{CO}_{3} \\
\mathrm{Li}_{\mathrm{x}} \mathrm{PO}_{\mathrm{y}} \mathrm{F}_{\mathrm{z}}\end{array}$ & $\mathrm{Li}_{2} \mathrm{CO}_{3}, \mathrm{LiF}$ & 60 \\
\hline $\mathrm{PES}^{\mathrm{a}}$ & $\begin{array}{c}\text { Full cell } \\
\left(\mathrm{NCM}_{\left.111 / \mathrm{SiO}_{\mathrm{x}}\right)}\right. \\
(2.5-4.2 \mathrm{~V})\end{array}$ & $\begin{array}{c}84 \\
(560 \text { cycles / 1 C) }\end{array}$ & $\begin{array}{c}\mathrm{Li}_{2} \mathrm{CO}_{3},-\mathrm{SO}_{3}, \\
-\mathrm{SO}_{4}, \mathrm{LiPF}_{\mathrm{x}}\end{array}$ & $\begin{array}{c}\mathrm{Li}_{2} \mathrm{CO}_{3},-\mathrm{SO}_{3}, \\
-\mathrm{SO}_{4}\end{array}$ & 61 \\
\hline FEC & $\begin{array}{c}\text { Full cell } \\
\text { (NCM523/Si-graphite) } \\
(2.5-4.1 \mathrm{~V})\end{array}$ & $\begin{array}{c}46.5 \\
(50 \text { cycles, C/3) }\end{array}$ & - & F-rich species & 62 \\
\hline
\end{tabular}

a) LiDFOB: lithium difluoro(oxalato)borate; PFPI: pentafluorophenyl isocyanate; TEOSCN: (2cyanoethyl)triethoxysilane; TMSPi: tris(trimethylsilyl)phosphite; PES: prop-1-ene-1,3-sultone; FEC: fluoroethylene carbonate. 


\section{SUPPLEMENTAL REFERENCES}

(1) Yu, Q.; Chen, Z.; Xing, L.; Chen, D.; Rong, H.; Liu, Q.; Li, W. Enhanced High Voltage Performances of Layered Lithium Nickel Cobalt Manganese Oxide Cathode by Using Trimethylboroxine as Electrolyte Additive. Electrochim. Acta 2015, 176, 919-925. https://doi.org/10.1016/j.electacta.2015.07.058.

(2) Wang, Z.; Xing, L.; Li, J.; Xu, M.; Li, W. Triethylborate as an Electrolyte Additive for High Voltage Layered Lithium Nickel Cobalt Manganese Oxide Cathode of Lithium Ion Battery. J. Power Sources 2016, 307, 587-592. https://doi.org/10.1016/j.jpowsour.2015.11.091.

(3) Mai, S.; Xu, M.; Liao, X.; Hu, J.; Lin, H.; Xing, L.; Liao, Y.; Li, X.; Li, W. Tris(trimethylsilyl)phosphite as Electrolyte Additive for High Voltage Layered Lithium Nickel Cobalt Manganese Oxide Cathode of Lithium Ion Battery. Electrochim. Acta 2014, 147, 565-571. https://doi.org/10.1016/j.electacta.2014.09.157.

(4) Murmann, P.; Streipert, B.; Kloepsch, R.; Ignatiev, N.; Sartori, P.; Winter, M.; CekicLaskovic, I. Lithium-cyclo-difluoromethane-1,1-bis(sulfonyl)imide as a Stabilizing Electrolyte Additive for Improved High Voltage Applications in Lithium-Ion Batteries. Phys. Chem. Chem. Phys. 2015, 17 (14), 9352-9358.

https://doi.org/10.1039/c5cp00483g.

(5) Zhang, L.; Ma, Y.; Cheng, X.; Zuo, P.; Cui, Y.; Guan, T.; Du, C.; Gao, Y.; Yin, G. Enhancement of High Voltage Cycling Performance and Thermal Stability of $\mathrm{LiNi}_{1 / 3} \mathrm{Co}_{1 / 3} \mathrm{Mn}_{1 / 3} \mathrm{O}_{2}$ Cathode by Use of Boron-based Additives. Solid State Ionics 2014, 263, 146-151. https://doi.org/10.1016/j.ssi.2014.06.001.

(6) Wang, Z.; Xing, L.; Li, J.; Li, B.; Xu, M.; Liao, Y.; Li, W. Trimethyl Borate as an Electrolyte Additive for High Potential Layered Cathode with Concurrent Improvement of Rate Capability and Cyclic Stability. Electrochim. Acta 2015, 184, 40- 
46. https://doi.org/10.1016/j.electacta.2015.10.044.

(7) Wang, C.; Yu, L.; Fan, W.; Liu, J.; Ouyang, L.; Yang, L.; Zhu, M. 3,3'-

(Ethylenedioxy)dipropiononitrile as an Electrolyte Additive for $4.5 \mathrm{~V}$

$\mathrm{LiNi}_{1 / 3} \mathrm{Co}_{1 / 3} \mathrm{Mn}_{1 / 3} \mathrm{O}_{2} /$ Graphite Cells. ACS Appl. Mater. Interfaces 2017, 9 (11), 9630 9639. https://doi.org/10.1021/acsami.6b16220.

(8) Zheng, X.; Huang, T.; Pan, Y.; Wang, W.; Fang, G.; Wu, M. High-Voltage

Performance of $\mathrm{LiNi}_{1 / 3} \mathrm{Co}_{1 / 3} \mathrm{Mn}_{1 / 3} \mathrm{O}_{2} /$ Graphite Batteries with Di(methylsulfonyl)

Methane as a New Sulfone-Based Electrolyte Additive. J. Power Sources 2015, 293, 196-202. https://doi.org/10.1016/j.jpowsour.2015.05.061.

(9) Zheng, X.; Huang, T.; Pan, Y.; Wang, W.; Fang, G.; Ding, K.; Wu, M. 3, 3'-

Sulfonyldipropionitrile: A Novel Electrolyte Additive that Can Augment the HighVoltage Performance of $\mathrm{LiNi}_{1 / 3} \mathrm{Co}_{1 / 3} \mathrm{Mn}_{1 / 3} \mathrm{O}_{2} /$ Graphite Batteries. J. Power Sources 2016, 319, 116-123. https://doi.org/10.1016/j.jpowsour.2016.04.053.

(10) Yan, C.; Xu, Y.; Xia, J.; Gong, C.; Chen, K. Tris(trimethylsilyl) Borate as an Electrolyte Additive for High-Voltage Lithium-Ion Batteries Using $\mathrm{LiNi}_{1 / 3} \mathrm{Mn}_{1 / 3} \mathrm{Co}_{1 / 3} \mathrm{O}_{2}$ Cathode. J. Energy Chem. 2016, 25 (4), 659-666. https://doi.org/10.1016/j.jechem.2016.04.010.

(11) Cai, H.; Jing, H.; Zhang, X.; Shen, M.; Wang, Q. Improving High-Voltage Performance of Lithium-Ion Batteries with Sulfolane as an Electrolyte Additive. $J$. Electrochem. Soc. 2017, 164 (4), A714-A720. https://doi.org/10.1149/2.0801704jes.

(12) Lee, S. H.; Yoon, S.; Hwang, E.-H.; Kwon, Y.-G.; Lee, Y.-G.; Cho, K. Y. [4,4'bi(1,3,2-dioxathiolane)] 2,2'-dioxide: A Novel Cathode Additive for High-Voltage Performance in Lithium Ion Batteries. J. Power Sources 2018, 378, 112-118. https://doi.org/10.1016/j.jpowsour.2017.12.026. 
(13) Qi, X.; Tao, L.; Hahn, H.; Schultz, C.; Gallus, D. R.; Cao, X.; Nowak, S.; Röser, S.; Li, J.; Cekic-Laskovic, I.; Rad, B. R.; Winter, M. Lifetime Limit of Tris(trimethylsilyl) Phosphite as Electrolyte Additive for High Voltage Lithium Ion Batteries. RSC Adv. 2016, 6 (44), 38342-38349. https://doi.org/10.1039/c6ra06555d.

(14) Dong, P.; Wang, D.; Yao, Y.; Li, X.; Zhang, Y.; Ru, J.; Ren, T. Stabilizing Interface Layer of $\mathrm{LiNi}_{0.5} \mathrm{Co}_{0.2} \mathrm{Mn}_{0.3} \mathrm{O}_{2}$ Cathode Materials under High Voltage Using $p$ Toluenesulfonyl Isocyanate as Film Forming Additive. J. Power Sources 2017, 344, 111-118. https://doi.org/10.1016/j.jpowsour.2017.01.116.

(15) Yan, G.; Li, X.; Wang, Z.; Guo, H.; Wang, C. Tris(trimethylsilyl)phosphate: A filmForming Additive for High Voltage Cathode Material in Lithium-Ion Batteries. $J$. Power Sources 2014, 248, 1306-1311. https://doi.org/10.1016/10.1016/j.jpowsour.2013.10.037.

(16) Yan, G.; Li, X.; Wang, Z.; Guo, H.; Peng, W.; Hu, Q.; Wang, J. Fluorinated Solvents for High-Voltage Electrolyte in Lithium-Ion Battery. J. Solid State Electrochem. 2017, 21 (6), 1589-1597. https://doi.org/10.1007/s10008-017-3508-4.

(17) Han, S.; Zhang, H.; Fan, C.; Fan, W.; Yu, L. 1,4-Dicyanobutane as a Film-Forming Additive for High-Voltage in Lithium-Ion Batteries. Solid State Ionics 2019, 337, 63 69. https://doi.org/10.1016/j.ssi.2019.03.027.

(18) Lee, Y.-M.; Nam, K.-M.; Hwang, E.-H.; Kwon, Y.-G.; Kang, D.-H.; Kim, S.-S.; Song, S.-W. Interfacial Origin of Performance Improvement and Fade for 4.6 V $\mathrm{LiNi}_{0.5} \mathrm{Co}_{0.2} \mathrm{Mn}_{0.3} \mathrm{O}_{2}$ Battery Cathodes. J. Phys. Chem. C 2014, 118 (20), 10631-10639. https://doi.org/10.1021/jp501670g.

(19) Su, C. C.; He, M.; Peebles, C.; Zeng, L.; Tornheim, A.; Liao, C.; Zhang, L.; Wang, J.; Wang, Y.; Zhang, Z. Functionality Selection Principle for High Voltage Lithium-ion Battery Electrolyte Additives. ACS Appl. Mater. Interfaces 2017, 9 (36), 30686-30695. 
https://doi.org/10.1021/acsami.7b08953.

(20) Liu, Y.; Sun, D.; Zhou, J.; Qin, Y.; Wang, D.; Guo, B. Isophorone Diisocyanate: An Effective Additive to Form Cathode-Protective-Interlayer and Its Influence on $\mathrm{LiNi}_{0.5} \mathrm{Co}_{0.2} \mathrm{Mn}_{0.3} \mathrm{O}_{2}$ at High Potential. ACS Appl. Mater. Interfaces 2018, 10 (13), 11305-11310. https://doi.org/10.1021/acsami.8b00011.

(21) Peebles, C.; Sahore, R.; Gilbert, J. A.; Garcia, J. C.; Tornheim, A.; Bareño, J.; Iddir, H.; Liao, C.; Abraham, D. P. Tris(trimethylsilyl) Phosphite (TMSPi) and Triethyl Phosphite (TEPi) as Electrolyte Additives for Lithium Ion Batteries: Mechanistic Insights into Differences during $\mathrm{LiNi}_{0.5} \mathrm{Mn}_{0.3} \mathrm{Co}_{0.2} \mathrm{O}_{2}$-Graphite Full Cell Cycling. $J$. Electrochem. Soc. 2017, 164 (7), A1579-A1586. https://doi.org/10.1149/2.1101707jes.

(22) Im, J.; Lee, J.; Ryou, M.-H.; Lee, Y. M.; Cho, K. Y. Fluorinated Carbonate-Based Electrolyte for High-Voltage $\mathrm{Li}\left(\mathrm{Ni}_{0.5} \mathrm{Mn}_{0.3} \mathrm{Co}_{0.2}\right) \mathrm{O}_{2} / \mathrm{Graphite}$ Lithium-Ion Battery. $J$. Electrochem. Soc. 2017, 164 (1), A6381-A6385. https://doi.org/10.1149/2.0591701jes.

(23) Wang, C.; Yu, L.; Fan, W.; Liu, R.; Liu, J.; Ouyang, L.; Yang, L.; Zhu, M. Enhanced High-Voltage Cyclability of $\mathrm{LiNi}_{0.5} \mathrm{Co}_{0.2} \mathrm{Mn}_{0.3} \mathrm{O}_{2}$-Based Pouch Cells via Lithium Difluorophosphate Introducing as Electrolyte Additive. J. Alloys Compd. 2018, 755, 19. https://doi.org/10.1016/j.jallcom.2018.05.005.

(24) Qin, Z.; Hong, S.; Hong, B.; Duan, B.; Lai, Y.; Feng, J. Triisopropyl Borate as an Electrolyte Additive for Improving the High Voltage Stability of $\mathrm{LiNi}_{0.6} \mathrm{Co}_{0.2} \mathrm{Mn}_{0.2} \mathrm{O}_{2}$ Cathode. J. Electroanal. Chem. 2019, 854, 113506. https://doi.org/10.1016/j.jelechem.2019.113506.

(25) Deng, B.; Wang, H.; Li, X.; Ding, Y.; Sun, D.; Ma, J.; Chen, M.; Chen, T.; Gao, F.; Qu, M.; Peng, G. Effects of Charge Cutoff Potential on an Electrolyte Additive for $\mathrm{LiNi}_{0.6} \mathrm{Co}_{0.2} \mathrm{Mn}_{0.2} \mathrm{O}_{2}-\mathrm{Mesocarbon}$ Microbead Full Cells. Energy Technol. 2019, 7 (4), 1800981. https://doi.org/10.1002/ente.201800981. 
(26) Deng, B.; Wang, H.; Ge, W.; Li, X.; Yan, X.; Chen, T.; Qu, M.; Peng, G. Investigating the Influence of High Temperatures on the Cycling Stability of a $\mathrm{LiNi}_{0.6} \mathrm{Co}_{0.2} \mathrm{Mn}_{0.2} \mathrm{O}_{2}$ Cathode Using an Innovative Electrolyte Additive. Electrochim. Acta 2017, 236, 6171. https://doi.org/10.1016/j.electacta.2017.03.155.

(27) Wang, S.; Chen, S.; Gao, W.; Liu, L.; Zhang, S. A New Additive 3Isocyanatopropyltriethoxysilane to Improve Electrochemical Performance of Li/NCM622 Half-Cell at High Voltage. J. Power Sources 2019, 423, 90-97. https://doi.org/10.1016/j.jpowsour.2019.03.046.

(28) Seok, J.-W.; Lee, J.; Rodgers, T.; Ko, D.-H.; Shim, J.-H. Effect of $\mathrm{LiPO}_{2} \mathrm{~F}_{2}$ Electrolyte Additive on Surface Electrical Properties of $\mathrm{LiNi}_{0.6} \mathrm{Co}_{0.2} \mathrm{Mn}_{0.2} \mathrm{O}_{2}$ Cathode. Trans. Electr. Electron. Mater. 2019, 20 (6), 548-553. https://doi.org/10.1016/10.1007/s42341-019-00151-5.

(29) Shi, C.-G.; Shen, C.-H.; Peng, X.-X.; Luo, C.-X.; Shen, L.-F.; Sheng, W.-J.; Fan, J.-J.; Wang, Q.; Zhang, S.-J.; Xu, B.-B.; Xian, J.-J.; Wei, Y.-M.; Huang, L.; Li, J.-T.; Sun, S.-G. A Special Enabler for Boosting Cyclic Life and Rate Capability of $\mathrm{LiNi}_{0.8} \mathrm{Co}_{0.1} \mathrm{Mn}_{0.1} \mathrm{O}_{2}$ : Green and Simple Additive. Nano Energy 2019, 65, 104084. https://doi.org/10.1016/j.nanoen.2019.104084.

(30) Jang, S. H.; Jung, K.; Yim, T. Silyl-Group Functionalized Organic Additive for High Voltage Ni-Rich Cathode Material. Curr. Appl. Phys. 2018, 18 (11), 1345-1351. https://doi.org/10.1016/j.cap.2018.07.016.

(31) Jang, S. H.; Yim, T. Effect of Silyl Ether-Functinoalized Dimethoxydimethylsilane on Electrochemical Performance of a Ni-Rich NCM Cathode. ChemPhysChem 2017, 18 (23), 3402-3406. https://doi.org/10.1002/cphc.201700921.

(32) Beltrop, K.; Klein, S.; Nölle, R.; Wilken, A.; Lee, J. J.; Köster, T. K. J.; Reiter, J.; Tao, L.; Liang, C.; Winter, M.; Qi, X.; Placke, T. Triphenylphosphine Oxide as Highly 
Effective Electrolyte Additive for Graphite/NMC811 Lithium Ion Cells. Chem. Mater. 2018, 30 (8), 2726-2741. https://doi.org/10.1021/acs.chemmater.8b00413.

(33) Li, J.; Liu, H.; Xia, J.; Cameron, A. R.; Nie, M.; Botton, G. A.; Dahn, J. R. The Impact of Electrolyte Additives and Upper Cut-off Voltage on the Formation of a Rocksalt Surface Layer in $\mathrm{LiNi}_{0.8} \mathrm{Mn}_{0.1} \mathrm{Co}_{0.1} \mathrm{O}_{2}$ Electrodes. J. Electrochem. Soc. 2017, 164 (4), A655-A665. https://doi.org/10.1149/2.0651704jes.

(34) Luo, Z.; Zhang, H.; Yu, L.; Huang, D.; Shen, J. Improving Long-Term Cyclic Performance of $\mathrm{LiNi}_{0.8} \mathrm{Co}_{0.15} \mathrm{Al}_{0.05} \mathrm{O}_{2}$ Cathode by Introducing a Film Forming Additive. J. Electroanal. Chem. 2019, 833, 520-526. https://doi.org/10.1016/j.jelechem.2018.12.041.

(35) Liu, B.; Li, Q.; Engelhard, M. H.; He, Y.; Zhang, X.; Mei, D.; Wang, C.; Zhang, J. G.; $\mathrm{Xu}, \mathrm{W}$. Constructing Robust Electrode/Electrolyte Interphases to Enable Wide Temperature Applications of Lithium-Ion Batteries. ACS Appl. Mater. Interfaces 2019, 11 (24), 21496-21505. https://doi.org/10.1021/acsami.9b03821.

(36) Yang, X.; Chen, J.; Zheng, Q.; Tu, W.; Xing, L.; Liao, Y.; Xu, M.; Huang, Q.; Cao, G.; Li, W. Mechanism of Cycling Degradation and Strategy to Stabilize a Nickel-Rich Cathode. J. Mater. Chem. A 2018, 6 (33), 16149-16163. https://doi.org/10.1039/c8ta03041c.

(37) Ping, P.; Wang, Q. S.; Sun, J. H.; Xia, X.; Dahn, J. R. Studies of the Effect of Triphenyl Phosphate on Positive Electrode Symmetric Li-Ion Cells. J. Electrochem. Soc. 2012, 159 (9), A1467-A1473. https://doi.org/10.1149/2.053209jes.

(38) Zheng, Q.; Xing, L.; Yang, X.; Li, X.; Ye, C.; Wang, K.; Huang, Q.; Li, W. N-Allyl- N, N-Bis(trimethylsilyl)amine as a Novel Electrolyte Additive to Enhance the Interfacial Stability of a Ni-Rich Electrode for Lithium-Ion Batteries. ACS Appl. Mater. Interfaces 2018, 10 (19), 16843-16851. https://doi.org/10.1021/acsami.8b00913. 
(39) Lyu, H.; Li, Y.; Jafta, C. J.; Bridges, C. A.; Meyer, H. M.; Borisevich, A.;

Paranthaman, M. P.; Dai, S.; Sun, X.-G. Bis(trimethylsilyl) 2-fluoromalonate

Derivatives as Electrolyte Additives for High Voltage Lithium Ion Batteries. J. Power

Sources 2019, 412, 527-535. https://doi.org/10.1016/j.jpowsour.2018.11.083.

(40) Han, G. B.; Lee, J. N.; Choi, J. W.; Park, J. K. Tris(Pentafluorophenyl) Borane as an Electrolyte Additive for High Performance Silicon Thin Film Electrodes in Lithium Ion Batteries. Electrochim. Acta 2011, 56 (24), 8997-9003.

https://doi.org/10.1016/j.electacta.2011.07.136.

(41) Lee, S. J.; Han, J. G.; Lee, Y.; Jeong, M. H.; Shin, W. C.; Ue, M.; Choi, N. S. A BiFunctional Lithium Difluoro(Oxalato)Borate Additive for Lithium Cobalt

Oxide/Lithium Nickel Manganese Cobalt Oxide Cathodes and Silicon/Graphite Anodes in Lithium-Ion Batteries at Elevated Temperatures. Electrochim. Acta 2014, 137, 1-8. https://doi.org/10.1016/j.electacta.2014.05.136.

(42) Hu, Z.; Zhao, L.; Jiang, T.; Liu, J.; Rashid, A.; Sun, P.; Wang, G.; Yan, C.; Zhang, L. Trifluoropropylene Carbonate-Driven Interface Regulation Enabling Greatly Enhanced Lithium Storage Durability of Silicon-Based Anodes. Adv. Funct. Mater. 2019, 29 (45), 1906548. https://doi.org/10.1002/adfm.201906548.

(43) Choi, N.-S.; Yew, K. H.; Lee, K. Y.; Sung, M.; Kim, H.; Kim, S. S. Effect of Fluoroethylene Carbonate Additive on Interfacial Properties of Silicon Thin-Film Electrode. J. Power Sources 2006, 161 (2), 1254-1259. https://doi.org/10.1016/j.jpowsour.2006.05.049.

(44) Chen, L.; Wang, K.; Xie, X.; Xie, J. Effect of Vinylene Carbonate (VC) as Electrolyte Additive on Electrochemical Performance of Si Film Anode for Lithium Ion Batteries. 
J. Power Sources 2007, 174 (2), 538-543.

https://doi.org/10.1016/j.jpowsour.2007.06.149.

(45) Dalavi, S.; Guduru, P.; Lucht, B. L. Performance Enhancing Electrolyte Additives for Lithium Ion Batteries with Silicon Anodes. J. Electrochem. Soc. 2012, 159 (5), 642646. https://doi.org/10.1149/2.076205jes.

(46) Han, G. B.; Ryou, M. H.; Cho, K. Y.; Lee, Y. M.; Park, J. K. Effect of Succinic Anhydride as an Electrolyte Additive on Electrochemical Characteristics of Silicon Thin-Film Electrode. J. Power Sources 2010, 195 (11), 3709-3714. https://doi.org/10.1016/j.jpowsour.2009.11.142.

(47) Nölle, R.; Achazi, A. J.; Kaghazchi, P.; Winter, M.; Placke, T. Pentafluorophenyl Isocyanate as an Effective Electrolyte Additive for Improved Performance of SiliconBased Lithium-Ion Full Cells. ACS Appl. Mater. Interfaces 2018, 10 (33), 2818728198. https://doi.org/10.1021/acsami.8b07683.

(48) Nguyen, C. C.; Lucht, B. L. Improved Cycling Performance of Si Nanoparticle Anodes via Incorporation of Methylene Ethylene Carbonate. Electrochem. commun. 2016, 66, 71-74. https://doi.org/10.1016/j.elecom.2016.03.005.

(49) Wang, J.; Zhang, L.; Zhang, H. Effects of Electrolyte Additive on the Electrochemical Performance of Si/C Anode for Lithium-Ion Batteries. Ionics (Kiel). 2018, 24 (11), 3691-3698. https://doi.org/10.1007/s11581-018-2682-4.

(50) Aupperle, F.; Von Aspern, N.; Berghus, D.; Weber, F.; Eshetu, G. G.; Winter, M.; Figgemeier, E. The Role of Electrolyte Additives on the Interfacial Chemistry and Thermal Reactivity of Si-Anode-Based Li-Ion Battery. ACS Appl. Energy Mater. 2019, 2 (9), 6513-6527. https://doi.org/10.1021/acsaem.9b01094. 
(51) Ryu, Y. G.; Lee, S.; Mah, S.; Lee, D. J.; Kwon, K.; Hwang, S.; Doo, S.

Electrochemical Behaviors of Silicon Electrode in Lithium Salt Solution Containing Alkoxy Silane Additives. J. Electrochem. Soc. 2008, 155 (8).

https://doi.org/10.1149/1.2940310.

(52) Jo, H.; Kim, J.; Nguyen, D. T.; Kang, K. K.; Jeon, D. M.; Yang, A. R.; Song, S. W. Stabilizing the Solid Electrolyte Interphase Layer and Cycling Performance of SiliconGraphite Battery Anode by Using a Binary Additive of Fluorinated Carbonates. $J$. Phys. Chem. C 2016, 120 (39), 22466-22475. https://doi.org/10.1021/acs.jpcc.6b07570.

(53) Xu, G.; Wang, X.; Li, J.; Shangguan, X.; Huang, S.; Lu, D.; Chen, B.; Ma, J.; Dong, S.; Zhou, X.; et al. Tracing the Impact of Hybrid Functional Additives on a HighVoltage (5 V-Class) $\mathrm{SiO}_{\mathrm{x}}-\mathrm{C} / \mathrm{LiNi}_{0.5} \mathrm{Mn}_{1.5} \mathrm{O}_{4} \mathrm{Li}$-Ion Battery System. Chem. Mater. 2018, 30 (22), 8291-8302. https://doi.org/10.1021/acs.chemmater.8b03764.

(54) Han, J.-G.; Lee, J. Bin; Cha, A.; Lee, T. K.; Cho, W.; Chae, S.; Kang, S. J.; Kwak, S. K.; Cho, J.; Hong, S. Y.; et al. Unsymmetrical Fluorinated Malonatoborate as an Amphoteric Additive for High-Energy-Density Lithium-Ion Batteries. Energy Environ. Sci. 2018, 11 (6), 1552-1562. https://doi.org/10.1039/c8ee00372f.

(55) Lee, D. J.; Im, D.; Ryu, Y.-G.; Lee, S.; Yoon, J.; Lee, J.; Choi, W.; Jung, I.; Lee, S.; Doo, S.-G. Phosphorus Derivatives as Electrolyte Additives for Lithium-Ion Battery: The Removal of $\mathrm{O}_{2}$ Generated from Lithium-Rich Layered Oxide Cathode. J. Power Sources 2013, 243, 831-835. https://doi.org/10.1016/j.jpowsour.2013.06.091. 
(56) Kim, Y. S.; Kim, T. H.; Lee, H.; Song, H. K. Electronegativity-Induced Enhancement of Thermal Stability by Succinonitrile as an Additive for Li Ion Batteries. Energy Environ. Sci. 2011, 4 (10), 4038-4045. https://doi.org/10.1039/c1ee01272j.

(57) Zuo, X.; Zhao, M.; Ma, X.; Xiao, X.; Liu, J.; Nan, J. Effect of Diphenyl Disulfide as an Additive on the Electrochemical Performance of $\mathrm{Li}_{1.2} \mathrm{Mn}_{0.54} \mathrm{Ni}_{0.13} \mathrm{Co}_{0.13} \mathrm{O}_{2} /$ Graphite Batteries at Elevated Temperature. Electrochim. Acta 2017, 245, 705-714. https://doi.org/10.1016/j.electacta.2017.05.155.

(58) Lee, H.; Choi, S. S.; Choi, S. S.; Kim, H. J.; Choi, Y.; Yoon, S.; Cho, J. J. SEI LayerForming Additives for $\mathrm{LiNi}_{0.5} \mathrm{Mn}_{1.5} \mathrm{O}_{4} /$ Graphite $5 \mathrm{~V}$ Li-Ion Batteries. Electrochem. commun. 2007, 9 (4), 801-806. https://doi.org/10.1016/j.elecom.2006.11.008.

(59) Zhang, B.; Metzger, M.; Solchenbach, S.; Payne, M.; Meini, S.; Gasteiger, H. A.; Garsuch, A.; Lucht, B. L. Role of 1,3-Propane Sultone and Vinylene Carbonate in Solid Electrolyte Interface Formation and Gas Generation. J. Phys. Chem. C 2015, 119, 11337-11348. https://doi.org/10.1021/acs.jpcc.5b00072.

(60) Deng, B.; Li, J.; Shang, H.; Liu, W.; Wan, Q.; Chen, M.; Qu, M.; Peng, G. Improving Cyclic Stability of $\mathrm{LiNi}_{0.6} \mathrm{Co}_{0.2} \mathrm{Mn}_{0.2} \mathrm{O}_{2}-\mathrm{SiO}_{\mathrm{x}} /$ Graphite Full Cell Using Tris(Trimethylsilyl)Phosphite and Fluoroethylene Carbonate as Combinative Electrolyte Additive. Ionics (Kiel). 2020, 1-11. https://doi.org/10.1007/s11581-01903396-5.

(61) An, F.; Zhao, H.; Zhou, W.; Ma, Y.; Li, P. S-Containing and Si-Containing Compounds as Highly Effective Electrolyte Additives for $\mathrm{SiO}_{\mathrm{x}}$-Based Anodes/NCM 811 Cathodes in Lithium Ion Cells. Sci. Rep. 2019, 9 (1), 1-16. https://doi.org/10.1038/s41598-019-49568-1. 
(62) Bareño, J.; Shkrob, I. A.; Gilbert, J. A.; Klett, M.; Abraham, D. P. Capacity Fade and Its Mitigation in Li-Ion Cells with Silicon-Graphite Electrodes. J. Phys. Chem. C 2017, 121 (38), 20640-20649. https://doi.org/10.1021/acs.jpcc.7b06118. 